\title{
STRATEGI IKONIK WISATA UNTUK MEMPERKENALKAN KOTA MALANG SEBAGAI SALAH SATU DESTINASI WISATA RELIGI
}

\author{
Moch. Musafa'ul Anam \\ Program Diploma Kepariwisataan Universitas Merdeka Malang \\ Jl. Bandung No.1 kota Malang
}

Korespondensi pada penulis:

Moch. Musafa'ul Anam, Telp: +6289 86368710

Email: musafaulanam@gmail.com

\begin{abstract}
Malang city has been known as one of the most favorite tourist destinations in Indonesia for several years. Thus, in order to keep its' achievement, this study tries to find out a new iconic strategy for promoting Malang as religion tourism destination. The study is a descriptive qualitative study which focused on direct observation and literature review in order to strengthen the findings. The result of this study shows that Malang is potentially able to be promoted as religion tourism destination. However, there are several points which should be prepared, done and developed such as: 1) conducting events which can promote Malang as religion tourism destination; 2) infrastructure and integrated-transportation developments; 3) building a spacious parking area; 4) continuous socialization to community; 5) continuous promotion through social medias; 6) Establishing an agency which will help Malang to be developed as religion tourism destination.
\end{abstract}

Keywords: Malang city; Promoting Malang city as Religion Tourism Destination; Tourism;

Kota malang merupakan salah satu kota yang terletak di provinsi Jawa Timur. Jaraknya sekitar 90 km arah selatan kota Surabaya dan merupakan kota kedua terbesar di Jawa Timur. Luas kota malang adalah $110.06 \mathrm{Km}^{2}$ terbagi dalam lima kecamatan yaitu: Klojen, Sukun, Lowokwaru, Blimbing, dan Kedungkandang. Seluruh wilayah kota Malang berbatasan langsung dengan kabupaten Malang. (malangkota.go.id).

Sebagai salah satu kota besar di Indonesia, kota malang memiliki beberapa sebutan yang sangat dikenal oleh masyarakat secara luas yaitu, kota bunga, kota pendidikan, kota pesiar, kota sejarah, hingga Paris van Oost Java atau dalam istilah Indonesia disebut 
dengan "Parisnya Jawa Timur". Nama tersebut disandang oleh kota Malang karena memiliki pemandangan yang indah, iklim yang sejuk serta kotanya yang bersih. Iklim sejuk tersebut bisa dirasakan karena kota Malang berada di ketinggan 440 - 667 mdpl dengan rata-rata suhu udara $21,6^{\circ} \mathrm{C}-24,7^{\circ} \mathrm{C}$ (Badan Pusat Statistik Kota Malang, 2014). Hal inilah yang membuat kota
Malang ramai dikunjungi wisatawan baik lokal maupun mancanegara.

Badan pusat Statistik kota Malang pada tahun 2015 mencatat sebanyak 3.385.476 orang wisatawan datang berkunjung ke Malang, dengan rincian 8.754 wisatawan asing dan 3.376.722 wisatawan domestik (BPS kota Malang, 2016). Secara lebih rinci, data bisa dilihat pada table dibawah ini:

Tabel 1. Data Kunjungan Wisatawan Asing dan Domestik ke Kota Malang Tahun 2015

\begin{tabular}{lccc}
\hline \multirow{1}{*}{$\begin{array}{c}\text { Bulan } \\
\text { Month }\end{array}$} & \multicolumn{2}{c}{$\begin{array}{c}\text { Wisatawan } \\
\text { Visitors }\end{array}$} & Jumlah \\
\cline { 2 - 4 } & $\begin{array}{c}\text { Mancanegara } \\
\text { International }\end{array}$ & $\begin{array}{c}\text { Domestik } \\
\text { Domestic }\end{array}$ & Total \\
\hline \multicolumn{1}{c}{$(1)$} & $(2)$ & $(3)$ & $(4)$ \\
\hline Januari/January & 725 & 282715 & 283440 \\
Februari/February & 718 & 185504 & 186222 \\
Maret/March & 524 & 202342 & 202866 \\
April/April & 498 & 194389 & 194887 \\
Mei/May & 481 & 203710 & 204191 \\
Juni/Juny & 654 & 247410 & 248064 \\
Juli/July & 706 & 271825 & 272531 \\
Agustus/August & 650 & 235388 & 236038 \\
September/September & 681 & 231498 & 232179 \\
Oktober/October & 674 & 253906 & 254580 \\
November/November & 769 & 310383 & 311152 \\
Desember/December & 1674 & 757652 & 759326 \\
\hline \multicolumn{1}{c}{ Jumlah/Total } & 8754 & 3376722 & 3385476 \\
\hline & & & \\
\hline
\end{tabular}

(Sumber: Badan Pusat Statistik kota Malang 2016) 
Tingginya jumlah wisatawan yang datang ke Malang menunjukkan bahwa kota ini masih menjadi salah satu tujuan wisata favorit. Prayogi (2017:12) mengatakan, bahwa kota Malang sangat berpotensi untuk dikembangkan, terutama yang berbasis dengan sumber daya lokal. Keberhasilan kota Malang dalam memajukan aspek pariwisatanya akan berdampak pada banyak hal seperti: perluasan kesempatan/peluang pekerjaan, pendorong pembangunan daerah, dan juga tambahnya pendapatan daerah (Wibisono, 2017:1). Wibisono (2017:2) juga mengatakan bahwa pengembangan wisata pada dasarnya bukan hanya berbicara tentang penambahan pendapatan daerah saja, namun lebih pada ajang untuk melestarikan asset pariwisata yang dimiliki. Oleh sebab itu, kota malang memerlukan satu konsep wisata baru yang mampu menarik lebih banyak turis untuk dapat berkujung ke Malang. Hal tersebut juga sejalan dengan apa yang telah dituangkan pemerintah kota Malang pada Isu Strategis pembangunan kota Malang tahun 2013-2018 yang salah satunya menginstruksikan agar pembangunan kota Malang diarahkan untuk dijadikan sebagai kota tujuan wisata yang didukung oleh potensi wisata religi, wisata kuliner dan wisata minat khusus (Laporan Kinerja Tahunan, 2015).

Berdasarkan ketiga potensi wisata yang telah dirumuskan pada Isu Strategis kota Malang tahun 20132018, wisata religi menjadi salah satu potensi pariwisata yang ingin dikembangkan oleh pemerintah kota. Hal ini dilakukan karena kota Malang memiliki banyak sekali bangunanbangunan tempat ibadah yang ikonik dan memiliki nilai sejarah yang cukup tinggi seperti contohnya masjid Agung Jami' Malang, klenteng Ang En Kiong, gereja Katedral Kayutangan dan masih banyak lagi. Bukan hanya itu saja, bicara masalah religi, di kota Malang juga ada beberapa kampung yang dihuni oleh mayoritas kelompok religi tertentu, seperti contohnya kampung arab (embong arab) dan pecinan yang mana disana juga terdapat rumahrumah tua bekas peninggalan Belanda. Namun, fenomena-fenomena tersebut tidak lantas membuat kota Malang dikenal sebagai salah satu kota tujuan wisata religi. Hal ini dikarenakan 
beberapa sebab yaitu: 1) Pemasaran wisata, 2) Infrastruktur, 3) Sarana wisata, 4) Peningkatan sumber daya manusia (SDM), 5) Karakter dan budaya masyarakat (Ilman dan Purwadio). Hal tersebut dikemukakan oleh Ilman dan Purwadio dalam penelitiannya yang dilakukan di kompleks Makam Syaihona Moh. Kholil Bangkalan. Secara lebih dalam mereka menyebutkan bahwa kompleks Makam Syaihona Moh. Kholil Bangkalan mengalami hambatan dalam pengembangannya karena insfrastruktur yang belum memadai. Hal yang kedua adalah, promosi yang belum secara maksimal dilakukan yang pada akhirnya berdampak pada cakupan pasar yang terbatas yaitu pada level lokal (Madura saja). Selanjutnya, pengelolaan obyek wisata yang belum maksimal, baik dari segi sumber daya manusia, keuangan, dan tata kelola.

Oleh karena itu, penelitian ini bertujuan untuk menemukan suatu strategi ikonik wisata untuk memperkenalkan kota malang sebagai salah satu destinasi wisata religi.

\section{METODE PENELITIAN}

Penelitian ini adalah penelitian deskriptif kualitatif. Penelitian ini bertujuan untuk memberikan deskripsi secara jelas, akurat dan faktual khususnya yang berhubungan dengan strategi pengembangan wisata religi di kota Malang. Pada penelitian ini deskriptif kualitatif ini peneliti menitik beratkan pada observasi. Oleh karena itu, pada penelitian ini peneliti hanya mengamati gejala-gejala dan mencatatnya sebagai bahan kajian. Setelah itu, dilakukan studi kepustakaan untuk memperkuat hasilhasil temuan dari observasi.

1. Tahapan Penelitian

Penelitian ini menggunakan dua teknik pengumpulan data, yaitu primer dan sekunder. Data primer pada penelitian ini dikumpulkan melalui observasi secara langsung pada objekobjek wisata religi seperti contohnya observasi langsung ke masjid Agung Jami' kota Malang meliputi sarana prasarana, tata kelola parkir, kesediaan toilet serta akses menuju masjid Agung Jami' 
kota Malang. Hal tersebut

dimaksudkan untuk

mengetahui bagaimana

keadaan objek-objek wisata religi secara langsung untuk dapat dianalisis kelebihan serta kekurangannya. Observasi secara langsung juga dilakukan agar mendapatkan data yang reliable serta akurat.

Data sekunder diperoleh dari studi kepustakaan yang dimaksudkan untuk memperkuat temuan-temuan yang didapatkan dari hasil obersvasi langsung oleh peneliti. Melalaui kegiatan studi kepustakaan ini juga dapat memberikan ide baru dalam menanggapi kekurangan-kekurangan yang terdapat pada obyek wisata religi.

2. Teknik Analisis

Penelitian ini menggunakan tiga teknik analisis data kualitatif yaitu:
Reduksi Data, Penyajian Data dan Penarikan Kesimpulan. Tahap pertama yang dilakukan adalah reduksi data. Reduksi data dilakukan untuk mempertajam kembali temuantemuan yang ditemujan selama observasi di obyek-obyek wisata religi untuk selanjutnya dicocokkan dengan studi pustaka. Tahap kedua adalah penyajian data-data yang sudah diolah dan disusun sedemikian rupa melalui tahap reduksi data sehingga memungkinkan untuk bisa ditarik kesimpulan. Pada penelitian kualitatif penyajian datanya berupa teks-teks desktriptif yang membahas lengkap tentang temuantemuan yang diperoleh selama proses pengambilan data. Tahap ketiga pada pelenitian ini adalah penarikan kesimpulan. Secara lebih ringkas, proses analisis data tersebut digambarkan seperti bagan dibawah ini: 


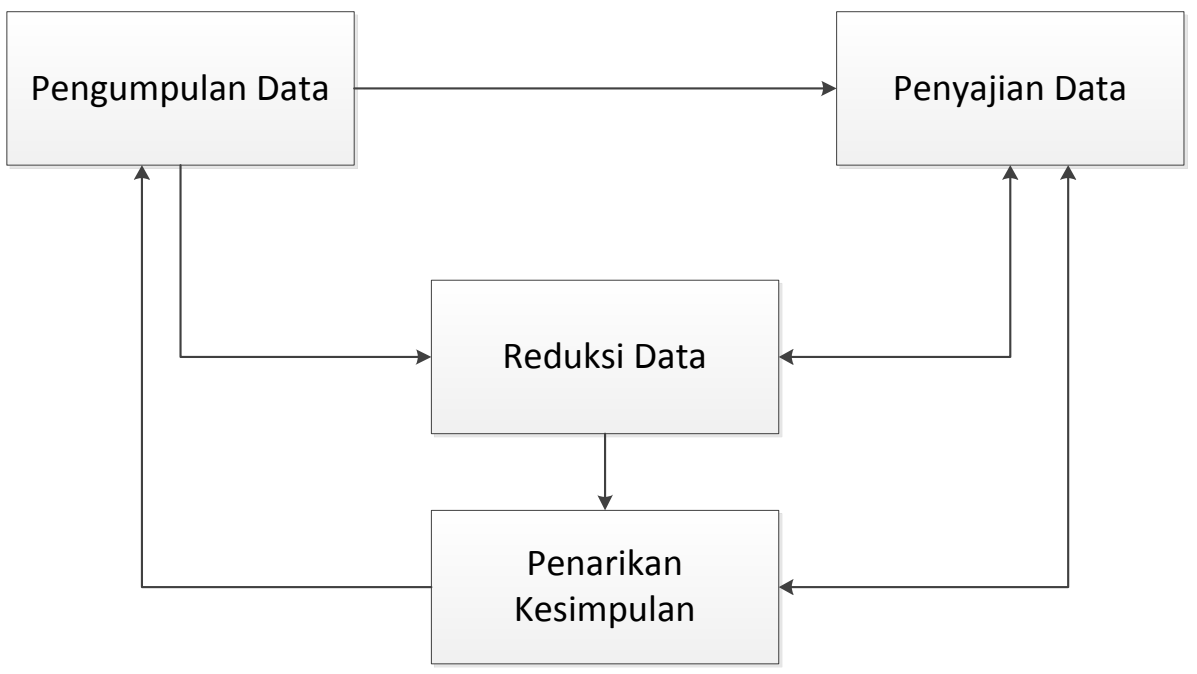

Gambar 1. Komponen Analisis Data Model Interaktif Miles dan Hubberman (1994)

Gambar diatas diadopsi dari gambar yang rancang oleh Miles dan Hubberman (1994) dalam Punch dan Oancea (2014: 224) pada bukunya yang berjudul Introduction to research methods in education. Gambar tersebut juga menunjukkan suatu proses atau siklus yang berlanjut dan terusmenerus. Dengan demikian, analisis data kualitatif merupakan proses yang akan terus dilakukan hingga mendapatkan hasil yang diinginkan atau memuaskan.

\section{HASIL DAN PEMBAHASAN}

Di era global seperti ini, paradigma masyarakat secara luas dalam melakukan perjalanan wisata kini sudah mulai bergeser, dari masyarakat yang hanya ingin menikmati atau sekedar mencari hiburan duniawinya saja, menjadi masyarakat yang melakukan perjalanan dikarenakan sebuah alasan "menambah pengetahuan", seperti yang sudah diungkapkan oleh Cohen (2006: 80) yakni "Some travel, of course, may be for purely recreational reasons. In general,however, travelers, spiritual seekers and students all hope to gain deeper and new understandings of the world and oneself. Pernyataan tersebut menguatkan pandangan bahwa masyarakat luas akan lebih tertarik untuk mengunjungi suatu obyek wisata yang mempunyai keunikan tidak hanya dari atraksi wisata yang disuguhkan, namun juga sisi budaya dan kehidupan sosial masyarakatnya (Cohen, 2006:81). Hal ini merupakan 
peluang yang besar dalam memperkenalkan kota Malang sebagai salah satu tujuan wisata sejarah dan edukasi terutama di bidang keagamaan/religi.

Berdasarkan pada apa yang telah dirumuskan pemerintah kota Malang melalui Isu Strategis Pembangunan kota Malang tahun 2013-2018 yang salah satunya memuat tentang pengembangan kota Malang sebagai kota tujuan wisata religi dan didukung dengan temuan-temuan di lapangan mengenai keadaan wisata religi di kota Malang, maka diperlukan suatu strategi yang tepat yang dapat diaplikasikan dalam rangka memajukan dan memperkenalkan wisata-wisata religi di Kota Malang. Menurut Ilman dan Purwadio, strategi-strategi tersebut diantara lain:

1. Penyelenggaraan kegiatan rutin yang mampu mempernalkan wisata-wisata religi kota Malang seperti: 1) Tabligh Akbar yang diselenggarakan tidak hanya di satu tempat (contoh Masjid Agung Jami'), namun ditempat-tempat lain; 2) Kirab Budaya Kong $\mathrm{Hu} \mathrm{Chu}$; 3)
Pawai Budaya Nusantara dll. Kegiatan tersebut diharapkan mampu menarik banyak wisatawan baik domestik maupun internasional untuk datang ke Malang.

2. Kegiatan promosi yang lebih menitik beratkan pada mediamedia modern seperti: 1) website; 2) Instagram; 3) Twitter; 4) Facebook dll. Tidak hanya kegiatan yang rutin digelar, namun promosi juga menjadi aspek yang cukup vital dalam pengembangan suatu kawasan wisata. Kegiatan seperti karnaval atau event besar lainnya sekalipun tidak akan pernah berhasil jika kegiatan promosinya tidak dilakukan dengan baik. Oleh karena itu, penggunaan mediamedia modern baik yang berbasis website maupun media social lainnya seperti facebook, twitter dan instagram diharapkan bisa menjadi sarana promosi yang tepat, cepat dan hemat.

3. Perencanaan dan pembangunan infrastruktur yang terintegerasi, 
serta penambahan city tour bus seperti bus MACITO (Malang City Tour Bus) yang mampu menjangkau tempat-tempat wisata religi. Perlu diketahui, saat ini bus Macito hanya melewati rute tertentu saja seperti kawasan kayutangan, jalan merdeka, dan jalan ijen yang mana tempat-tempat tersebut hanya terdapat sekitar 4 (buah) bangunan tempat ibadah yang bersejarah. Sedangkan kawasan-kawasan lain seperti kebalen dan embong arab tidak dilewati. Satu hal yang juga perlu digaris bawahi adalah bus Macyto hanya melewati tempat-tempat bersejarah itu. Hal itu membuat wisatawan hanya bisa menikmati keindahan bangunan secara tampak fisik tanpa mengetahui sejarah dobelakangya. Kedua, bus Macyto hanya melayani tour pada hari weekend saja mulai pukul 09.00 - 11.00 pagi. Waktu 3 jam tersebut dirasa cukup singkat bagi wisatawan untuk dapat menikmati perjalanan mereka. Ketiga, bus Macyto hanya bisa dinaiki/diakses dari depan gedung DPRD kota Malang saja. Kedepan, perlu di bangun tempat-tempat pemberhentian lain yang memudahkan para wisatawan untuk dapat mengakses bus Macyto.

4. Perencanaan dan pembangunan tempat parkir yang luas, aman, dan tertib. Adanya tempat parkir yang luas membuat para wisatawan bisa dengan leluasa memarkirkan kendaraan mereka tanpa bingung tidak kebagian tempat parkir. Parkir yang aman membuat para wisatawan merasa tenang ketika meninggalkan kendaraan mereka. Sedangkan, parkir yang tertib dan tertata membuat para pengguna jalan serta wisatawan lain merasa tetap nyaman dengan adanya kegiatan wisata yang sedang berlangsung.

5. Sosialisasi berkala dan terus menerus kepada masyarakat untuk dapat menjaga lingkungan sebagai bentuk 
peran serta mereka dalam menyukseskan program ini. Karena dengan tanpa adanya lingkungan yang bersih, minat wisatawan untuk berkunjung ke salah satu tempat wisata religi juga akan menurun.

6. Pembentukan satu badan pengelolaan wisata religi kota Malang. Seperti yang telah dibahas sebelumnya, pengelolaan secara swadaya masyarakat tidak akan mampu mencapai target yang dicapai untuk menjadikan kota Malang sebagai kota wisata religi. Oleh karena itu diperlukan peran serta pemerintah pemerintah dalam membentuk sebuah badan yang memang berfokus untuk mengelola dan mengembangkan kawasan wisata religi kota malang seperti apa yang telah diungkapkan oleh Wibisono (2017:9). Badan pengelola yang dibentuk harus juga berkolaborasi dengan akademisi untuk menciptakan satu sinergi dalam rangka memperkenalkan kota Malang sebagai salah satu destinasi wisata religi. Supriadi (2016) mengatakan bahwa setelah semua hubungan terjalin dengan baik, selanjutnya diperlukan adanya pendampingan secara berkala pada pengelola. Hal tersebut bisa dilakukan dengan cara seperti: Orientasi dan kegiatan pelatihan sensitivitas kelompok, pertemuan yang efektif, pelatihan tentang teknik mengambil keputusan, memberikan pendampingan dalam perbaikan pengelolaan, melakukan kunjungan ke tobjek wisata yang didampingi serta pengembangan instrument evaluasi pendampingan.

\section{Kesimpulan}

Tingginya tingkat kunjungan wisatawan ke kota Malang merupakan satu bukti bahwa kota ini masih menjadi tujuan wisata favorit pengunjung baik dari dalam maupun luar negeri. Namun hal ini haruslah di tunjang dengan adanya satu konsep pariwisata baru semisal wisata religi. Hal tersebut sangat mungkin untuk 
direalisasikan mengingat bahwa kota Malang memiliki banyak sekali situs wisata religi misalnya saja: masjid Agung Jami' Malang, klenteng Ang En Kiong, gereja Katedral Kayutangan, gereja Katedral Ijen, kampung arab (embong arab), pecinan dan lain-lain. Oleh karena itu, sebagai upaya dalam memperkenalkan kota Malang sebagai salah satu destinasi wisata religi, ada beberapa hal harus dilakukan seperti: penyelenggaraan kegiatan rutin sebagai sarana promosi, pembangunan infrastruktur serta sarana transportasi yang terintegerasi, pembangunan tempat parkir yang luas, sosialisasi berkala kepada masyarakat, promosi berbasis media sosial, serta pembentukan satu badan pengelolaan wisata religi kota Malang sebagai center unit yang mengelola segala proses perencanaan hingga pengembangan kota Malang sebagai salah satu tujuan wisata religi nasional.

\section{DAFTAR RUJUKAN} . Keadaan Geografi kota Malang (Online). Diakses melalui: http://malangkota.go.id/sekil as-malang/geografis/ pada 24 Agustus 2017.
Badan Pusat Statistik kota Malang. (2015). STATISTIK DAERAH KOTA MALANG 2014. Malang: Badan Pusat Statistik.

Badan Pusat Statistik kota Malang. (2016). STATISTIK DAERAH KOTA MALANG 2015. Malang: Badan Pusat Statistik.

Cohen, Erick H. (2006). Religious tourism as an educational experience. Dallen J. Timothy dan Daniel H. Olsen (Eds.), Tourism, Religion and Spiritual Journeys. New York: Routledge

Ilman, Anas, \& Purwadio, Heru. (__). Pengembangan Kawasan Wisata Religi kompleks Makam Syaihona Moh.Kholil Bangkalan. Diakses melalui http://digilib.its.ac.id/public/IT S-paper-33957-3606100013Paper.pdf pada 26 Juli 2017.

Prayogi, D. (2017). Pengembangan Potensi Wisata Kuliner Kota Malang Berbasis Sumber Daya Lokal. Jurnal Pariwisata Pesona, 2(1), 13. Diakses melalui: http://jurnal.unmer.ac.id/index. php/jpp/article/view/1260/843

Punch, K. F., \& Oancea, A. (2014). Introduction to research methods in education. Sage.

Supriadi, B. (2016). Kompetensi Pendampingan Pemandu Wisata Lokal sebagai Developers of People. Jurnal Pariwisata Pesona, 1(2). Retrieved from http://jurnal.unmer.ac.id/index. php/jpp/article/view/517

Wibisono, A. (2017). Peningkatan Kesejahteraan Hidup Masyarakat melalui Pengembangan Eco- 
Homestay di Desa Ampelgading Kecamatan Tirtoyudo Kabupaten Malang. Jurnal Pariwisata Pesona, 2(1), 11. Retrieved from http://jurnal.unmer.ac.id/index. php/jpp/article/view/1250 